\title{
LIMBAH PELEPAH PISANG RAJA SUSU SEBAGAI ALTERNATIF BAHAN DINDING KEDAP SUARA
}

\author{
Suharyani, Dhani Mutiari \\ Program Studi Teknik Arsitektur, Fakultas Teknik, Universitas Muhammadiyah Surakarta \\ Jl. A. Yani Tromol Pos 1 Pabelan Kartasura Sukoharjo 57102 Telp 0271-717417 \\ E-mail: yani.ummumufti@gmail.com
}

\begin{abstract}
ABSTRAK
Beberapa hal yang dapat mempengaruhi kenyamanan di dalam ruangan diantaranya adalah perencanaan sistem pencahayaan, penghawaan dan akustik dapat berfungsi optimal. Kenyamanan dalam ruangan akan terwujud apabila bisa mengatasi masalah kebisingan yang terjadi baik dari dalam maupun dari luar ruangan. Kemajuan sarana transportasi menjadi salah satu penyebab masalah kebisingan. Pemilihan material yang kurang tepat juga menjadi penyebab kebisingan. Reduksi bunyi dapat terjadi tergantung jenis material penyerapannya, yaitu material yang memiliki nilai penyerapan lebih tinggi dari pada nilai pantulnya. Pemilihan material akustik menjadi penentu kualitas suara di dalam ruangan. Beberapa fungsi suatu bangunan memiliki persyaratan tingkat intensitas bunyi yang distandarkan. Bahan material yang diproduksi oleh pabrik dan sering dijumpai adalah glaswool, karpet, sterofoo,. Beberapa penelitian terdahulu telah mengujikan beberapa alternatif bahan dinding kedap suara dengan memanfaatkan potensi lokal, diantaranya adalah dengan menggunakan bahan dasar sekam padi, sabut kelapa dan serbuk gergaji kayu. Pada penelitian ini limbah pelepah pisang menjadi pilihan untuk bahan dasar dinding kedap suara. Selain harganya murah, bahan ini sering dijumpai dan mudah untuk memperolehnya. Hasil penelitian menunjukkan bahwa serat pelepah pisang memenuhi persyaratan penting dari karakteristik dasar bahan akustik yaitu, bahan berpori yang memiliki jaringan selular dengan pori-pori yang saling berhubungan. Tingkat kepadatan pelepah pisang yang sudah dikeringkan akan semakin membuat pelepah pisang menjadi bahan yang dapat menyerap bunyi dengan cukup baik dan akan meredamnya.Pelepah pisang yang sudah dikeringkan, memilki tekstur yang berserabut dan berpori. Hal ini bisa menjadi alternatif bahan dasar material dinding kedap suara. Jenis pisang yang digunakan pada penelitian ini adalah pisang raja susu yang dinilai lebih murah dan lebih banyak terdapat disekitar lingkungan rumah.
\end{abstract}

Kata Kunci: dinding kedap suara, material, nilai reduksi bunyi, pelepah pisang raja susu

\section{PENDAHULUAN \\ Menggali potensi lokal dengan peman- faatan limbah alami}

Segala sesuatu yang diciptakan oleh Allah SWT pasti memilki nilai kebaikan. Kekayaan alam yang melimpah di alam semesta ini merupakan salah satu bukti kebesaran Nya. Kekayaan alam dengan berbagai macam bentuk dan warna tumbuhtumbuhan yang ada di sekitar kita telah membuktikan kekuasaan dan kebesaran Allah. Hal ini dijelaskan dalam Alquran surat
Asy Syu'araa' ayat 7 : Artinya: "Dan apakah mereka tidak memperhatikan bumi, berapakah banyaknya Kami tumbuhkan di bumi itu pelbagai macam tumbuh-tumbuhan yang baik".

Beberapa jenis tumbuhan/tanaman yang ada di negara Indonesia memiliki nilai kemanfaatan yang besar. Salah satu diantaranya adalah pohon pisang. Tanaman ini mudah didapatkan, memiliki beberapa manfaat, dan harga relatif murah. Pohon pisang sering dijumpai di lingkungan sekitar 
kita. Pohon pisang sering dijumpai di setiap pekarangan rumah, di pinggir jalan serta di sawah-sawah di pedesaan. Pohon pisang di Indonesia menjadi salah satu komoditas yang dapat dimanfaatkan. Pisang dikonsumsi oleh semua kalangan masyarakat. Pisang dijual dengan berbagai tingkatan mutu dan harga yang sangat bervariasi satu sama lain. Indonesia memiliki lebih dari 230 jenis pisang. Dari beberapa jenis pisang di Indonesia hanya beberapa jenis pisang yang dijual di pasaran, dikonsumsi oleh masyarakat dan mudah untuk mendapatkannya, diantaranya adalah : Pisang Barangan, Raja, Raja Sereh (Raja Susu), Raja Uli, Raja Jambe, Raja Molo, Raja Kul, Raja Tahun, Raja Bulu, Kepok, Tanduk, Mas, Ambon Lumut, Ambon Kuning, Nangka, Kapas, Kidang, Lampung, dan pisang Tongkat Langit. Pohon pisang memiliki banyak keistimewaan dibanding jenis tanaman yang lain. Penelitian terdahulu menyebutkan bahwa pelepah pisang Kepok bisa menjadi alternatif bahan dinding kedap suara. Pisang Raja Susu dipilih karena jumlahnya melimpah dan harganya lebih murah dibandingkan dengan pisang kepok. Pelepah pisang Raja Susu juga memiliki karakteristik hampir sama dengan pisang kepok.

\section{Dinding kedap suara untuk mengatasi masalah akustik dalam ruangan}

Akustik adalah ilmu yang mempelajari tentang bunyi dan semua yang berkaitan dengan bunyi serta cara penanggulangan cacat akustik. Hal-hal yang dipelajari dalam akustik meliputi: sifat-sifat bunyi, usaha mendapatkan bunyi yang enak untuk di dengar dalam sebuah ruangan, isolasi bunyi, persyaratan akustik dan sebagainya.

Bunyi adalah gelombang getaran mekanis dalam udara atau benda padat yang masih bisa terdengar oleh telinga normal manusia. Getaran tersebut ada pada frekuensi 20-20000 Hertz. Di bawah rentang tersebut disebut bunyi infra (infra sound), sedang di atas rentang tersebut disebut bunyi ultra (ultra sound). Suara (voice) adalah bunyi manusia. Bunyi udara (airborne sound) adalah bunyi yang merambat lewat udara. Bunyi struktur (structural sound) adalah bunyi yang merambat melalui struktur bangunan.Alat untuk mengukur besarnya bunyi atau tekanan suara yang keluar dari sumbernya adalah sound level meter. Satuan bunyi adalah sound level meter.

Akustik ruang lebih membahas tentang kualitas bunyi dalam ruang dan pengaturannya, pengendalian cacat akustik, bising. Kebisingan/noise adalah bunyi yang mengganggu dan tidak diinginkan, berasal dari suara manusia, lalu-lintas kendaraan, mesin/peralatan, refleksi suara speaker. Bunyi akan terdengar dari sumbernya apabila kenyaringannya melebihi background noise minimal $6 \mathrm{~dB}$ sampai $10 \mathrm{~dB}$. Batas minimal perubahan kenyaringan bunyi yang masih dapat didengar dalam kondisi normal adalah 3 $\mathrm{dB}$. Reduksi bising alamiah dapat terjadi karena aspek suhu udara $\left({ }^{\circ} \mathrm{C}\right)$, kelembaban udara $(\% \mathrm{RH})$. Semakin tinggi suhu, kelembapan rendah dan intensitas bunyi naik (Satwiko, 2004).

Kebisingan juga dapat didefinisikan sebagai berikut:

1. Menurut Keputusan Menteri Tenaga Kerja No.KEP-51/MEN/1999 menyebutkan bahwa kebisingan adalah semua suara yang tidak dikehendaki yang bersumber dari alat-alat proses produksi dan atau alat-alat kerja yang berada pada titik tertentu dapat menimbulkan gangguan pendengaran.

2. Sedangkan menurut Peraturan Menteri Kesehatan R.I. No.718/MENKES/PER/ $\mathrm{XI} / 1987$ tentang kebisingan yang berhubungan dengan kesehatan bahwa kebisingan adalah terjadinya bunyi yang tidak dikehendaki sehingga mengganggu dan membahayakan kesehatan.

Apabila akan membangun sebuah ruangan yang digunakan untuk aktifitas yang berkaitan dengan suara, misalnya home theater dan studio ataupun ruang rapat/konferensi dan ruang konser, ada 2 hal yang harus diperhatikan, yang pertama adalah bagaimana membuat ruangan terisolasi secara akustik dari lingkungan sekitarnya atau sering disebut sebagai insulasi (membuat ruangan kedap suara atau soundproof). Hal lain yang harus diperhatikan adalah bagaimana mengkondisikan ruangan agar berkinerja sesuai dengan fungsinya atau sering disebut sebagai pengendalian medan akustik ruangan. 


\section{Penerapan dinding kedap suara}

Dinding kedap suara terdiri dari beberapa jenis komposisi material. Bahan yang biasa digunakan adalah karpet dan glaswool. Dinding bata atau beton, dilapisi
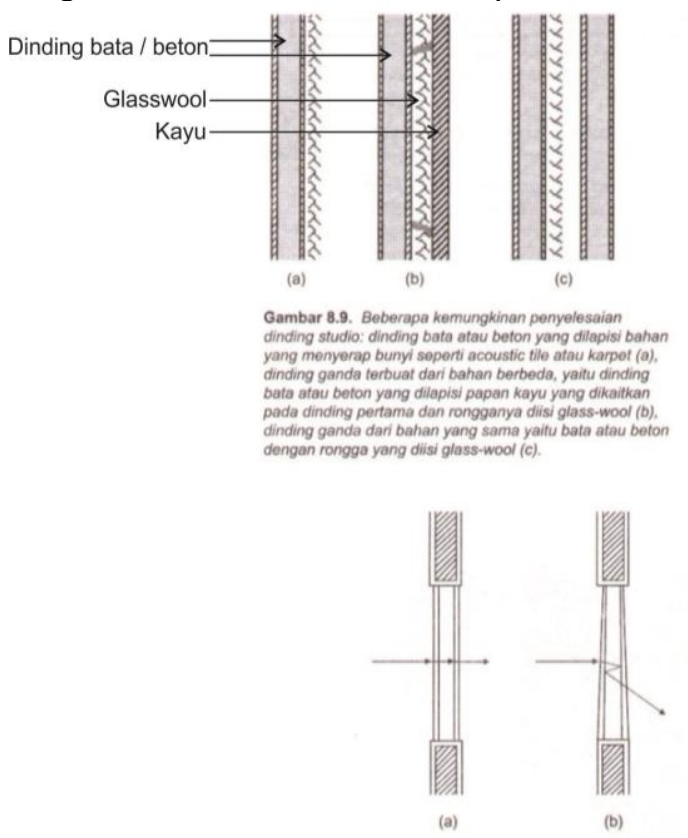

karpet atau glasswool, yang diletakkan diantara dinding bata dan kayu.

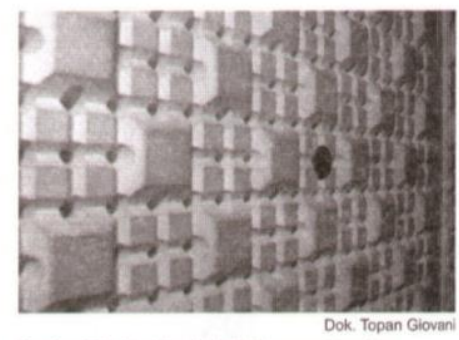

Gambar 8.10. Contoh peiapis dinding yang digunaka! pada sebuah studio musik

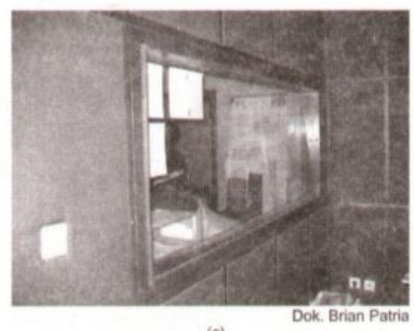

Gambar 1. Contoh dinding kedap suara dengan bahan glaswool (Sumber : Mediastika, 2002)

\section{Akustik dalam Ruangan}

Bunyi akan mudah terbentur pembatas ruang di tempat tertutup. Pada ruangan tersebut akan terjadi peristiwa refleksi, absorbsi, transmisi, difraksi, difusi ,tergantung karakteristik elemen pembatas ruang (jenis material, luas, bentuk). Bunyi terdengar merupakan kombinasi bunyi asli dan bunyi pantul. Penekanan pada cara mengatasi kebisingan yang muncul di dalam ruang serta meningkatkan kualitas bunyi, hal ini bertujuan agar tidak terjadi cacat akustik.

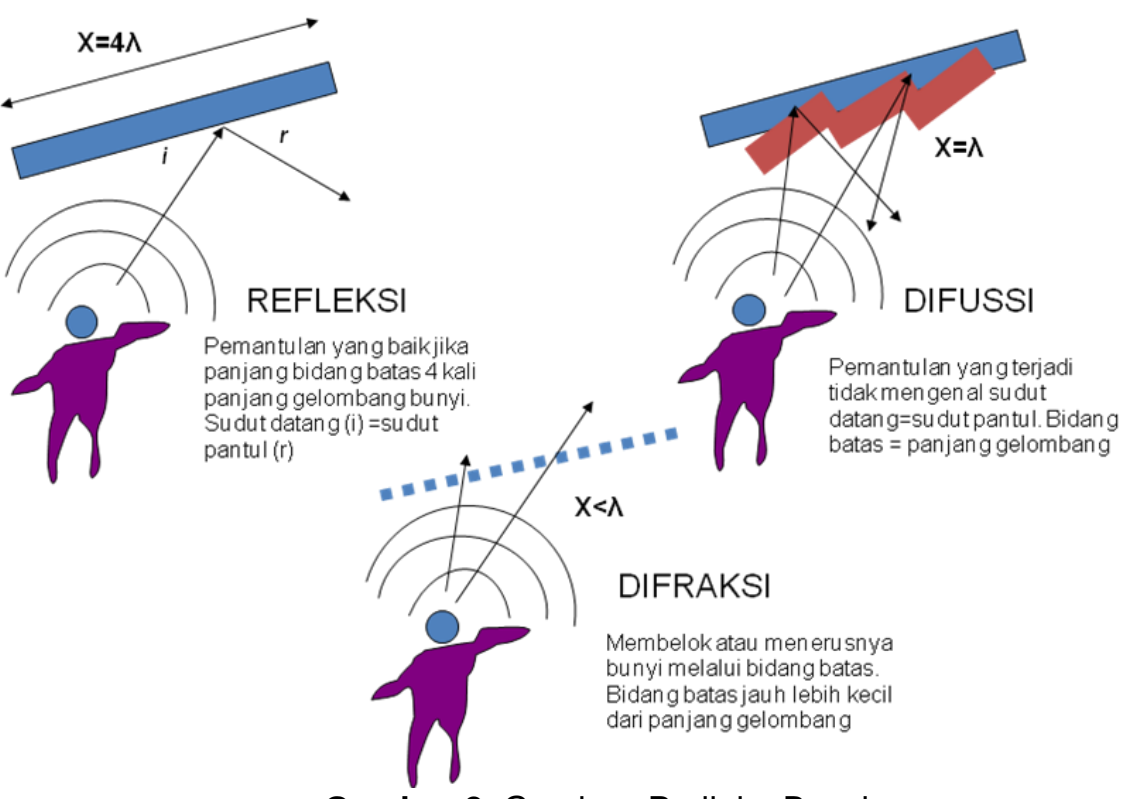

Gambar 2. Gambar Perilaku Bunyi (Sumber : Mediastika, 2005) 


\section{Reduksi Bunyi}

Reduksi bunyi dapat terjadi tergantung jenis material penyerapannya,. Material yang memiliki nilai penyerapan lebih tinggi dari pada nilai pantulnya. Nilai penyerapan bunyi dari seluruh elemen ruang yang dinaikkan $2 x$ lipat dari nilai semula, maka akan menurunkan kebisingan (dari proses pantulan) sebesar $3 \mathrm{~dB}$. Nilai reduksi bunyi setelah ada pergantian material dirumuskan sebagai berikut :

$\mathrm{NR}=10 \log \frac{a 2}{a 1}$

dengan

$\mathrm{NR}=$ Noise Reduction $(\mathrm{dB})$

a2 = total reduksi setelah re-design

a1 $=$ total reduksi sebelum re-design

NR merupakan reduksi dari bunyi hasil pemantulan yang tidak dikehendaki dengan penggantian elemen bidang batas, dengan intensitas sumber bunyi adalah tetap. Bagian elemen ruang yang harus mendapat perhatian agar NR efektif adalah bagian plafon, karena bagian ini merupakan bidang yang bebas dari kemungkinan tertutup objek lain, sehingga sangat potensial memantulkan bunyi.

\section{Koefisien Penyerapan/Absorbsi ( $\alpha$ )}

Koefisien penyerapan adalah jumlah/proporsi dari keseluruhan energi yang datang yang mampu diserap oleh material. Nilai koefisien penyerapan 1 mengandung arti bahwa permukaan menyerap (absorbsi) dengan sempurna, nilai penyerapan 0 berarti permukaan memantulkan (refleksi) dengan sempurna.Udara memiliki koefisien serap 0,007 dan dihitung dalam frekwensi $2000 \mathrm{~Hz}$.

Tabel 1. Material dan Koefisien Serap

\begin{tabular}{|c|c|}
\hline MATERIAL & $\begin{array}{c}\text { KOEFISIEN SERAP } \\
\text { PADA 500 Hz }\end{array}$ \\
\hline Semen & 0,015 \\
\hline Semen lapis keramik & 0,01 \\
\hline Semen lapis karpet tebal & 0,14 \\
\hline Semen lapis kayu & 0,10 \\
\hline Batu bata ekspos & 0,06 \\
\hline Papan kayu & 0,10 \\
\hline Tirai sedang/tebal & $0,49 / 0,55$ \\
\hline Kaca buram & 0,04 \\
\hline Eternit & 0,17 \\
\hline Gyosum & 0,05 \\
\hline Manusia & 0,46 \\
\hline
\end{tabular}

(Sumber : SK 405/MenKes RI/SK/XI/2002) 


\section{Pelepah Pisang sebagai Alternatif Bahan Dinding Kedap Suara}

Serat yang diperoleh dari pelepah pisang merupakan serat yang cukup kuat sehingga cocok dijadikan bahan kain (textil). Serat ini juga cocok digunakan sebagai bahan baku pembuatan kertas karena memiliki memiliki kekuatan dan daya simpan yang tinggi (Suyanti dkk, 2008 hal 30). Karakteristik dari serat pada pelepah pisang yang bisa digunakan sebagai pengganti bahan pembuat kain dan juga berdaya simpan tinggi, sehingga serat pisang memenuhi syarat sebagai bahan akustik untuk penyerapan bunyi. Serat pelepah pisang juga memenuhi persyaratan penting dari karakteristik dasar bahan akustik yaitu, bahan berpori yang memiliki jaringan selular dengan pori-pori yang saling berhubungan. Apalagi setelah pelepah pisang dikeringkan untuk mengurangi kandungan air pada pelepah pisang tersebut, maka kepadatannya akan semakin membuat pelepah pisang menjadi bahan yang dapat menyerap bunyi dengan cukup baik dan akan meredamnya.

Pelepah pisang yang sudah dikeringkan, memilki tekstur yang berserabut dan berpori. Hal ini sebenarnya bisa juga menjadi alternatif bahan dasar material dinding kedap suara. Beberapa penelitian terdahulu telah menguji beberapa alternatif bahan dinding kedap suara yang memiliki karakteristik hampir sama dengan pelepah pisang yang dikeringkan, sebagai contoh diantaranya adalah: sabut kelapa, sekam padi dan limbah gergaji kayu.

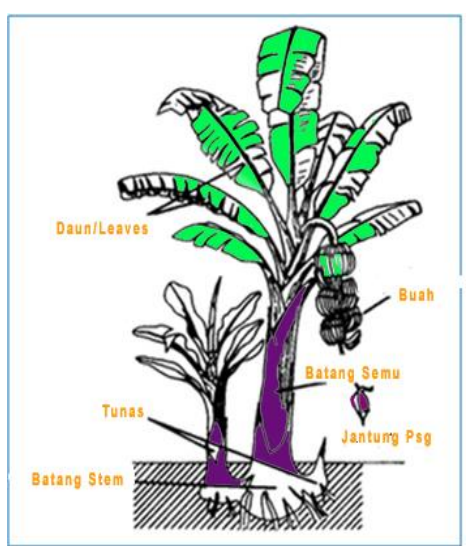

Gambar 3. Morfologi tanaman pisang

Sumber : http://sulut.litbang.deptan.go.id

Elemen penyerap bunyi yang berpori mempunyai karakteristik penyerapan lebih efisien. Selain itu, ketebalan dan jarak lapisan dinding juga menentukan optimalisasi tingkat peredaman terhadap bunyi. Bahan berpori ini antara lain: serat mineral, serat-serat karang (rock wool), serat-serat gelas (glass wool), serat-serat kayu, karpet, kain dan sebagainya.

Hampir seluruh bagian tanaman pisang memiliki nilai kemanfaatan. Tingginya permintaan pasar akan hasil olahan buah pisang menimbulkan masalah yaitu limbah, seperti kulit pisang, bunga (jantung pisang), pelepah (batang) dan bonggol (akar). Akan tetapi limbah tersebut masing-masing memiliki nilai guna.

Semakin berkembangnya ilmu pengetahuan maka limbah-limbah tersebut bisa di diolah kembali, sehingga menghasilkan produk-produk baru yang memiliki nilai ekonomis dan nilai guna yang lebih tinggi. Pelepah pisang bisa diolah sehingga menghasilkan produk alternatif bahan dinding kedap suara.

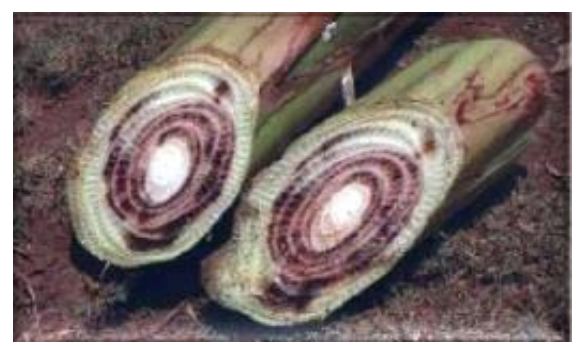

Gambar 4. Batang pisang

Sumber: Suharyani, 2012

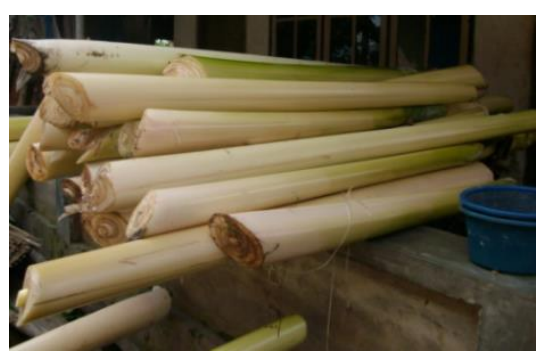

Gambar 5. Pelepah pisang yang akan dikeringkan Sumber: Suharyani, 2012

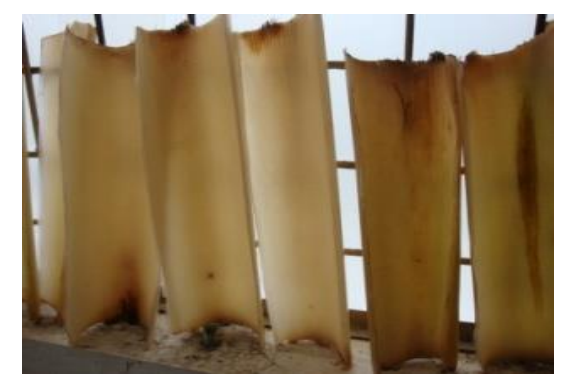

Gambar 6. Pelepah pisangyang akan dikeringkan Sumber: Suharyani, 2012 


\section{METODE PENELITIAN}

Metode yang digunakan adalah dengan studi komparasi dengan penelitian-penelitian terdahulu. Metode Eksperimental juga digunakan untuk menguji kemampuan penyerapan bunyi yang dihasilkan dari bahan pelepah pisang dengan berbagai bentuk anyaman yang berbeda dan memilki kemampuan paling optimum dalam meredam bunyi.

Metode yang dilakukan untuk mengetahui nilai reduksi bunyi yang dihasilkan diantaranya adalah membuat beberapa jenis anyaman dari pelepah pisang yang sudah dikeringkan. Pelepah pisang yang sudah dipilih dikeringkan, kemudian dibuat anyaman. Anyaman tersebut kemudian diberi pelapis finishing triplek, agar bisa digunakan sebagai partisi dinding. Pengujian material ini dilakukan di laboratorium akustik, yaitu dengan membawa bahan uji untuk diujikan di laboratorium.

\section{HASIL DAN PEMBAHASAN}

Nilai reduksi bunyi yang dihasilkan dari pelepah pisang sebagai dinding kedap suara merupakan salah satu masalah yang dibahas pada penelitian ini. Pengukuran waktu dengung dilakukan sebelum uji material. Pengukuran tingkat reverberation dalam sebuah ruangan dilakukan dengan menggunakan waktu dengung (reverberation time). Waktu dengung dibutuhkan oleh suatu sumber bunyi yang dihentikan seketika untuk turun intensitasnya sebanyak $60 \mathrm{~dB}$ dari intensitas awal (Mediastika, 2005).

Ruangan pengujian akustik yang digunakan berukuran 3,6 X 3,6X2,4 m dengan hitungan waktu dengung (t) sebesar 0,26 detik. Memiliki data sebagai berikut :kapasitas 2 orang dengan koefisien serap 0,46 , di mana volume ruang $3,6 \times 3,6 \times 2,4=31,104 \mathrm{~m}^{3}$, dinding dilapisi glaswool koefisien serap 0,30 luas $4 \times(3,6 \times 2,4)=34,56 \mathrm{~m}^{2}$, luas lantai dan plafon masing-masing 3,6 X 3,6 = 12,96 $\mathrm{m}^{2}$ dan dilapisi glaswool dengan koefisien serap 0,30. Meja kayu : 1 X 0,6 dengan koefisien serap 0,10 , kursi plastik 1 buah dengan koefisien serap 0,01 , dinding panel akustik dengan bahan pelepah pisang yang akan diujikan seluas $(1 \times 0,45) \mathrm{m}^{2}$.

Rumus waktu dengung (reverberation time)pada saat ruangan kosong atau belum dipasang panel akustik yang akan diujikan, dihitung dengan rumus sebagai berikut:

$t=\frac{0,16 \cdot \mathrm{V}}{\Sigma \cdot \mathrm{A} \cdot \alpha}$

$\mathrm{t}=$ waktu dengung (detik)

$\mathrm{V}=$ volume ruang $\left(\mathrm{m}^{3}\right)$

$A=$ luas permukaan bidang penyerapan

$\alpha=$ koefisien atau tingkat penyerapan suatu permukaan bidang

Perhitungan ini akan digunakan pada penelitian lanjutan dengan mencari waktu dengung ( $\mathrm{t}$ ) pada ruangan uji akustik dan perubahannya setelah dipasang material dinding kedap suara dngan bahan limbah pelepah pisang.

\section{KESIMPULAN}

Pemilihan material akustik menjadi penentu kualitas suara di dalam ruangan. Beberapa fungsi suatu bangunan memiliki persyaratan tingkat intensitas bunyi yang distandarkan. Bahan material yang diproduksi oleh pabrik dan sering dijumpai adalah glaswool, karpet, sterofoom, Beberapa penelitian terdahulu telah mengujikan beberapa alternatif bahan dinding kedap suara dengan memanfaatkan potensi lokal, diantaranya adalah dengan menggunakan bahan dasar sekam padi, sabut kelapa dan serbuk gergaji kayu. Pada penelitian ini limbah pelepah pisang menjadi pilihan untuk bahan dasar dinding kedap suara. Selain harganya murah, bahan ini sering dijumpai dan mudah untuk memperolehnya. Serat pelepah pisang juga memenuhi persyaratan penting dari karakteristik dasar bahan akustik yaitu, bahan berpori yang memiliki jaringan selular dengan pori-pori yang saling berhubungan. Tingkat kepadatan pelepah pisang yang sudah dikeringkan akan semakin membuat pelepah pisang menjadi bahan yang dapat menyerap bunyi dengan cukup baik dan akan meredamnya. Pelepah pisang yang sudah dikeringkan, memiliki tekstur yang berserabut dan berpori. Hal ini bisa menjadi alternatif bahan dasar material dinding kedap suara. Penelitian selanjutnya bisa dilakukan pengujian lebih lanjut lagi tentang nilai reduksi yang dihasilkan dari dinding kedap suara dari bahan pelepah pisang. Metode yang digunakan dalam membuat material dinding 
kedap suara dari bahan pelepah pisang juga perlu dikaji lebih dalam untuk mengetahui hubungan pola anyaman kaitannya dengan kemampuan nilai reduksi bunyi dan hubungannya dengan nilai estetika dari bentuk tampilan material yang akan dihasilkan.

\section{DAFTAR PUSTAKA}

Khuriati, Aini, dkk, 2006, Disain Peredam Suara Berbahan Dasar Sabut Kelapa dan Pengukuran Koefisien Penyerapan Bunyinya, Berkala Fisika ISSN : 1410 - 9662, Vol.9 No.11, Januari 2006, 15-25

Mediastika, 2005, Akustika Bangunan, Prinsip-prinsip dan Penerapannya di Indonesia, Edisi I, Erlangga, Jakarta

Mediastika, 2009, Material Akustik, Pengendali Kualitas Bunyi pada Bangunan, Edisi I, Andi, Yogyakarta

M. Bagus, 2009, Pemanfaatan Komposit Serat Batang PisangUntuk Aplikasi Panel Dinding Kendaraan Umum Kedap Suara Dan Memiliki Sifat Mekanik Yang Kuat, 5 Oktober 2011,http://blog.its.ac.id/bagus0390

Satwiko, Prasasto, 2004, Fisika Bangunan Edisi 1,ANDI, Yogyakarta

Satwiko, Prasasto, 2004, Fisika Bangunan Edisi 2,ANDI, Yogyakarta 